\title{
Significados em puérperas da internaçao na Unidade de terapia intensiva $^{\dagger}$
}

\author{
Significados en puérperas sobre la hospitalización en Unidad de Cuidados Intensivos \\ Significance in postpartum women about hospitalization in the Intensive Care Unit \\ Laura Vanessa Osorio-Contreras* \\ Nubia Castiblanco-López ${ }^{* *}$
}

\section{Resumo}

Objetivo: Descrever o significado desde o olhar cultural que atribuem puérperas com morbidade materna extrema a sua internação na Unidade de Terapia Intensiva (UTI). Materiais e Métodos: Estudo qualitativo com abordagem etnográfica, utilizou-se como referente teórico a Madeleine Leininger. As entrevistas a profundidade e a análise qualitativa realizou-se considerando o método de James Spradley. Obtiveram-se 21 entrevistas a profundidade em 9 mulheres puérperas com morbidade materna extrema e estiveram internadas numa UTI de uma clínica da cidade de Sincelejo, Sucre, Colômbia entre março e dezembro de 2017. Resultados: Os significados que atribuíram as puérperas com morbidade materna extrema respeito à sua internação na UTI incluíram oito domínios: conhecimento dos sinais de alarma, temor da morte, muito difícil para o meu parceiro, adiamento da amamentação, retorno à clinica, minha família cuida de mim, a enfermeira me cuida e aprender dessa experiência. Conclusões: Os significados de puérperas com morbidade materna extrema estão carregados de experiências, crenças culturais e sentimentos, onde o cuidado compassivo e congruente de enfermagem ajuda na sua sobrevivência e a internação na UTI constitui-se num ensinamento para a vida.

Palavras-chave: Período pós-parto, terapia intensiva, enfermagem, cultura

\section{Resumen}

Objetivo: Describir el significado desde lo cultural que atribuyen puérperas con Morbilidad Materna Extrema a su hospitalización en la Unidad de Cuidados Intensivos. Materiales y Métodos: Estudio cualitativo con abordaje etnográfico, utilizando como referente teórico a Madeleine Leininger. Las entrevistas a profundidad y el análisis cualitativo se realizaron teniendo en cuenta el método de James Spradley. Se efectuaron 21 entrevistas a profundidad a 9 puérperas con Morbilidad Materna

$\dagger$ Este artículo es producto de la investigación "Significados de puérperas con Morbilidad Materna Extrema sobre su hospitalización y la del hijo(a) prematuro". Requisito para optar al título de Magíster en Enfermería con énfasis en Cuidado para la salud Materno Perinatal. Adscrita al Grupo de Investigación Cuidado Materno Perinatal. Línea de investigación: Cuidado de enfermería a la familia y el recién nacido prematuro y Bajo Peso al Nacer en Programa Madre Canguro de la Facultad de Enfermería - Universidad Nacional de Colombia.
Autor de correspondencia

* Enfermera. Maestrante en Enfermería con énfasis en Cuidado Materno Perinatal. Enfermera. Clínica Especializada La Concepción. Correo: lauryvanessa@gmail.com. Orcid: https://orcid.org/0000-0003-44799451. Sincelejo, Colombia.

** Enfermera. Magíster en Enfermería con énfasis en Cuidado Materno Perinatal. Profesora Asociada. Universidad Nacional de Colombia. Correo. ncastiblancol@unal.edu. co. Orcid: https://orcid.org/0000-0003-13907923. Bogotá, Colombia. 
ISSN-PRINT

1794-9831

E-ISSN 2322-7028

Vol. 16 No. 3

Sep - Dic 2019

Cúcuta, Colombia

Extrema que estuvieron hospitalizadas en la Unidad de Cuidados Intensivos de una clínica de la ciudad de Sincelejo-Sucre - Colombia entre marzo y diciembre de 2017. Resultados: Los significados que atribuyen puérperas con Morbilidad Materna Extrema sobre su hospitalización en la Unidad de Cuidados Intensivos incluyeron 8 dominios: conocimiento de los signos de alarma, temor a morir, muy difícil para mi compañero, aplazar la lactancia materna, de regreso a la clínica, mi familia me cuida, la enfermera me cuida y aprender de esta experiencia. Conclusiones: Los significados de puérperas con Morbilidad Materna Extrema están colmados de experiencias, creencias culturales y sentimientos, donde el cuidado compasivo y congruente de enfermería les ayuda a sobrevivir y la hospitalización en la UCI se constituye en una enseñanza para la vida.

Palabras Clave: Periodo posparto, Near Miss Salud, unidad de cuidados intensivos, enfermería y cultura

\begin{abstract}
Objective: Describe the significance from the cultural view conferred by postpartum women with Maternal Near Miss about their hospitalization in the Intensive Care Unit. Materials and methods: Qualitative study with ethnographic approach, using as theoretical reference Madeleine Leininger. The in-depth interviews and the qualitative analysis were made considering the method of James Spradley. 21 in-depth interviews were performed on 9 puerperal women with Maternal Near Miss who were hospitalized in the Intensive Care Unit in a clinic in the city of Sincelejo-Sucre-Colombia between March and December 2017. Results: The significance attributed by postpartum women with Maternal Near Miss about their hospitalization in the Intensive Care Unit included 8 domains: knowledge about alarm symptoms, fear of death, difficulty for my partner, postponing breastfeeding, going back to the clinic, my family takes care of me, the nurse takes care of me and learning from this experience. Conclusions: The significance of puerperal women with Maternal Near Miss are full of experiences, cultural beliefs and feelings, where compassionate and congruent nursing care helps them survive and hospitalization at the ICU constitutes a life lesson.
\end{abstract}

Keywords: Postpartum period, maternal near-miss, intensive care unit, nursing and culture.

\section{Introdução}

O número de casos nos que se apresentam complicações que ameaçam a vida da mulher na gestação, parto e puerpério estão em aumento (1). O 75\% das mortes maternas nas Américas são consequência de hemorragias graves e infecções, especialmente após o parto; a hipertensão gestacional, pré-eclâmpsia e eclâmpsia; complicações no parto e abortos perigosos (2). Assim, a primeira semana de vigilância epidemiológica do ano 2019 na Colômbia reportou o crescimento significativo nos casos de morte materna nos estados de Sucre, Nariño, Tolima, Valle e Vaupés (3).

As taxas de morbidade materna extrema (MME) são maiores em países emergentes. Na América Latina foi de 5,1\% (3) e na Colômbia a meados de 2017 foram reportados 23.157 casos no Sistema Nacional de Vigilância em Saúde Pública (SIVIGILA) (4); de estas o $41,2 \%$ foi internada na Unidade de Terapia Intensiva (UTI), sendo as principais causas de MME a pre-eclâmpsia severa no $69,3 \%$ dos casos, seguida da hemorragia obstétrica severa $(14,8 \%)$ e no terceiro lugar a infecção sistémica severa (6,8\%) (5).
Em relação aos dados anteriores, Ortiz y Ludmir (6) mencionaram que embora na América Latina os indicadores mostrem melhoras significativas no acesso à atenção pré-natal e de parto com pessoal treinado e qualificado, estes avances não tem sido suficientes, na Colômbia as gestantes continuam falecendo por complicações derivadas da gravidez, parto e puerpério, isto é evidente pelos 487 casos confirmados de morte materna no pais no ano 2017 (7).

Neste ponto, é importante enfatizar que as políticas de saúde tem-se focado no melhoramento da acessibilidade no controle pré-natal. Além disso, deve-se garantir a abordagem no tratamento oportuno e integral às pacientes e que os casos mais severos sejam encaminhados as instituições de saúde mais complexas onde forneçam acompanhamento multidisciplinar, devido às múltiplas "condições fisiológicas e patológicas das gestantes as tornam um desafio medico"(8), razões que geram incertezas e medo na equipe de saúde que incorre em erros no relacionado com o atendimento.

É significativo considerar que o atendimento à gestante e puérpera de alto risco gera impacto emocio- 
nal para ela e à sua família. $\mathrm{O}$ fato de sobreviver à situações de MME demanda maior acompanhamento, informação à puérpera e o casal, favorecendo a compreensão e as mudanças que isto traz para os seus estilos de vida físicos e psicológicos (9).

Elmir e col (10) também fortalecem a importância do acompanhamento e seguimento posterior ao evento de MME, onde deve-se prestar a oportunidade à puérpera de falar da sua experiência, sento estes espaços fundamentais para ajudar à redução dos sintomas emocionais e psicológicos nesta população.

Na revisão realizada por Furuta e col (11) encontraram que as percepções e experiências de mulheres com MME estão influenciadas pelas suas características pessoais, as condições de saúde pré-existentes, a sensação de segurança durante os atendimentos, a disponibilidade e acessibilidade do atendimento médico de alta qualidade e as redes de apoio social. Assim mesmo, Vasconcelos e col (12) afirmaram que para as gravidas e puérperas, ações como: cálidas boas-vindas ao hospital, explicações claras sobre as doenças e os procedimentos a serem realizados durante a internação, são aspectos importantes para reduzirem o medo, promover o bem-estar físico e mental nessas pacientes.

Por outro lado, Ospina e col (13) afirmaram que o puerpério é uma etapa que precisa de acompanhamento acorde às necessidades informadas pelas pacientes, assim como a educação em saúde respeito às mudanças fisiológicas do corpo feminino, os cuidados com a criança recém nascida e a amamentação, facilitam o afrontamento e adaptação da mãe aos novos desafios e mais para frente, a reintegração à sua vida social e laboral.

Partindo do anterior, descobrir o significado da internação na UTI em puérperas com MME contribui no sentido social, disciplinar e teórico da enfermagem. Neste ponto, é preciso frisar que o profissional de enfermagem encarregado de prestar atenção direta à puérpera com MME, é quem conhece de perto o impacto emocional da doença pelo afastamento do seu filho prematuro, promovendo afinidade e empatia entre a puérpera e a enfermeira (o); igualmente, permite fornecer o cuidado holístico, porque conhece e interpreta o que a sua paciente precisa, as suas necessidades emocionais, espirituais, físicas ou de ensino, o que pode providenciar para ajuda-la e contri- buir com a sua recuperação, convertendo-a numa profissional que presta cuidados sensíveis e responsáveis.

Neste sentido, é fundamental conhecer estes significados desde a perspectiva cultural. Cárdenas (14) considerou a MME como um problema de saúde pública complexo, influenciado pelas condições individuais da mulher grávida, pela qualidade dos serviços médicos e o contexto social e cultural. Do mesmo modo, González (15) destacou a necessidade de conhecer mais sobre os aspectos culturais, principalmente pelas razões que a gestante tem e justificam a demora em procurar atenção e acudir aos serviços de saúde, baseadas nas suas crenças culturais e que não receberá atendimento. Assim mesmo, Carrillo e col afirmam que existem vazios de equidade de etnia no estado do Meta (Colômbia), pela presença de mais de vinte assentamentos indígenas, portanto Marin (17) sustenta à importância de aprofundar no conhecimento da relação entre a mortalidade e a MME com determinantes económicos e culturais.

Por outro lado Castiblanco e col (18) encontraram que as puérperas costumam cuidar dos recém nascidos prematuros no seu lar, seguindo as recomendações do seu contexto cultural, isto traduzido em rutinas diárias que acompanham as crenças dos avós. Igualmente, Hoyos (19), afirmou que as mães tem maneiras próprias de estabelecer o apego com os seus filhos mediante práticas da sua cultura, assim como as mães do litoral caribe referem-se ao toque físico como "manuseio". Entretanto, não há evidência científica de estudos realizados em puérperas com morbidade materna internadas na UTI com abordagem cultural.

Tendo presente os postulados de Leininger (20) na sua teoria sobre a universalidade e diversidade do cuidado cultural, que evidenciou a importância à maneira do cuidado humano para a recuperação da saúde, a conservação da saúde e o bem-estar, considerando que as pessoas tem as suas próprias maneiras de cuidar-se, tornou-se um desafiou às enfermeiras para descobrir o cuidado específico e holístico empregado pelas diferentes culturas através do tempo; teoria que fundamentou a análise do presente estudo.

Segundo o anterior, o presente trabalho centra os seus resultados sobre os significados de puérperas com morbidade materna extrema sobre a sua internação na UTI, pesquisa que faz parte do estudo "significados de puérperas com morbidade materna extrema sobre a sua internação e a do seu filho prematuro"(21). 
ISSN-PRINT

1794-9831

E-ISSN 2322-7028

Vol. 16 No. 3

Sep - Dic 2019

Cúcuta, Colombia

\section{Objetivo general}

Explorar o significado que atribuem as puérperas com morbidade materna extrema à sua internação na unidade de terapia intensiva

\section{Objetivo específico}

Analisar o significado que atribuem as puérperas com mortalidade materna extrema à sua internação na unidade de terapia intensiva alicerçadas na teoria de Madeleine Leininger.

\section{Materiales y Métodos}

Utilizou-se à pesquisa qualitativa de abordagem etnográfica, empregando o método de Etno-enfermagem da Madeleine Leininger e a entrevista a profundidade do James Spradley. Primeiro, o método da Leininger facilitou a proximidade com as puérperas para colher os dados com maior precisão , sem afasta-la dos seus costumes, crenças práticas e entorno familiar (22).

Estudaram-se 9 puérperas com os seguintes critérios de inclusão: mulheres no pós-parto, maiores de 15 anos, que voluntariamente assinassem o termo de consentimento livre y esclarecido, com critérios de MME definidos pelo protocolo de vigilância em saúde pública da Colômbia do ano 2016, que estiveram internadas na UTI e que o seu filho prematuro estivesse também internado na unidade de terapia neonatal.

As participantes foram captadas numa clínica na cidade de Sincelejo (Colômbia), posteriormente, programaram-se visitas domiciliares no seu lar, procurando um ambiente tranquilo, livre de barulho ou distrações, onde foram realizadas as entrevistas com uma duração aproximada de 40 minutos. Estas entrevistas foram gravadas e transcritas textualmente. No processo de coleta da informação, utilizaram-se os facilitadores Observação-Participação-Reflexão (OP$\mathrm{R})$ e amigo-estranho. A OP-R permitiu entrar no mundo das informantes e permanecer nele durante todo o tempo de estudo (14). O facilitador amigo-estranho facilitou estabelecer conexão com as informantes, obtendo dados autênticos, críveis e confiáveis (23). Assim mesmo, preencheram-se anotações de campo na ordem cronológica, com datas, horas, situações ou lugares no período de realização das entrevistas (25).

A amostra de participantes, determinou-se com critérios de pertinência, adequação, conveniência, oportu- nidade e disponibilidade até cumprir com os critérios de saturação teórica (24), que foi obtida ao comple$\operatorname{tar} 21$ entrevistas. A informação obtida foi analisada alicerçada na teoria do sol nascente e estabeleceu-se segundo os três tipos de cuidados culturais: conservação, adaptação e reestruturação.

Posteriormente, utilizou-se a guia de entrevista etnográfica de uso livre proposta por Spradley (26) que consta de 12 etapas: localização do informante, fazer o registro etnográfico, fazer perguntas descritivas $(\mathrm{O}$ quê significou estar internada na UTI depois da cesariana?), análise da entrevista etnográfica, fazer a análise cultural (terminologia empregada, domínios e relações semânticas), fazer perguntas estruturais (Como você sabe que a sua pressão arterial está elevada? ), fazer análise taxonômica (procurando a estrutura interna dos domínios), fazer perguntas de contraste (Como tem sido a experiência deste pós-parto comparado com o anterior?), fazer análise de componentes (compreende procurar atributos em cada domínio para comparar com a literatura), descobrir as temáticas culturais e escrever uma etnografia.

Para análise da informação criaram-se os seguintes códigos: I: Informante, acompanhado da numeração de 1-9 correspondente ao número do participante. E: entrevista, com a sua respectiva numeração de 1-3 correspondente à informação obtida na primeira, segunda ou terceira entrevista realizada.

Para o desenvolvimento deste estudo tiveram-se presentes rigorosamente os critérios metodológicos da pesquisa qualitativa (credibilidade, transferibilidade, confirmabilidade e consistência). Entre as considerações éticas incluiu-se a Resolução 008430/1993 que estabelece a normatividade para a realização de pesquisa em saúde na Colômbia, igualmente a aprovação da comissão de ética da Universidad Nacional de Colombia e da Clínica.

\section{Resultados}

As informantes foram 9 puérperas com MME que estiveram internadas na UTI numa clínica na cidade de Sincelejo- Sucre, com idades entre 17 e 35 anos, 5 eram casadas e 4 conviviam em união estável; a escolaridade das puérperas esteve entre o ensino fundamental e pós-graduação; 2 residiam numa cidade de outro estado (Chinú-Córdoba), 1 em Betulia-Sucre e 1 na região rural de Las Palmas de Sincelejo, as de- 
mais em bairros na zona urbana de Sincelejo. À forma de vinculação ao sistema de saúde 1 era do plano de saúde e 8 do setor público.

Nos antecedentes obstétricos, 2 foram primigestas e 7 multigestas, realizaram-se entre 2 e 7 atendimentos pré-natais e o tempo de internação na UTI esteve entre 4 e 22 dias. $O$ diagnostico de internação na UTI em 8 das mulheres foi a pré-eclâmpsia severa, 2 delas com complicações como a síndrome de HELLP e uma além disso mio-cardiopatia Peri-parto; a outra paciente foi internada na UTI por choque hipovolêmico secundário à descolamento da placenta.

Depois da análise das entrevistas surgiu o tema relacionado com os significados das puérperas com MME sobre a sua internação na UTI, evidenciando os domínios: conhecimento dos sinais de alarme, medo de morrer, muito difícil para o meu parceiro, adiamento da amamentação, voltar à clínica, a minha família cuida de mim, a enfermeira me cuida e aprender dessa experiência (ver Figura 1).

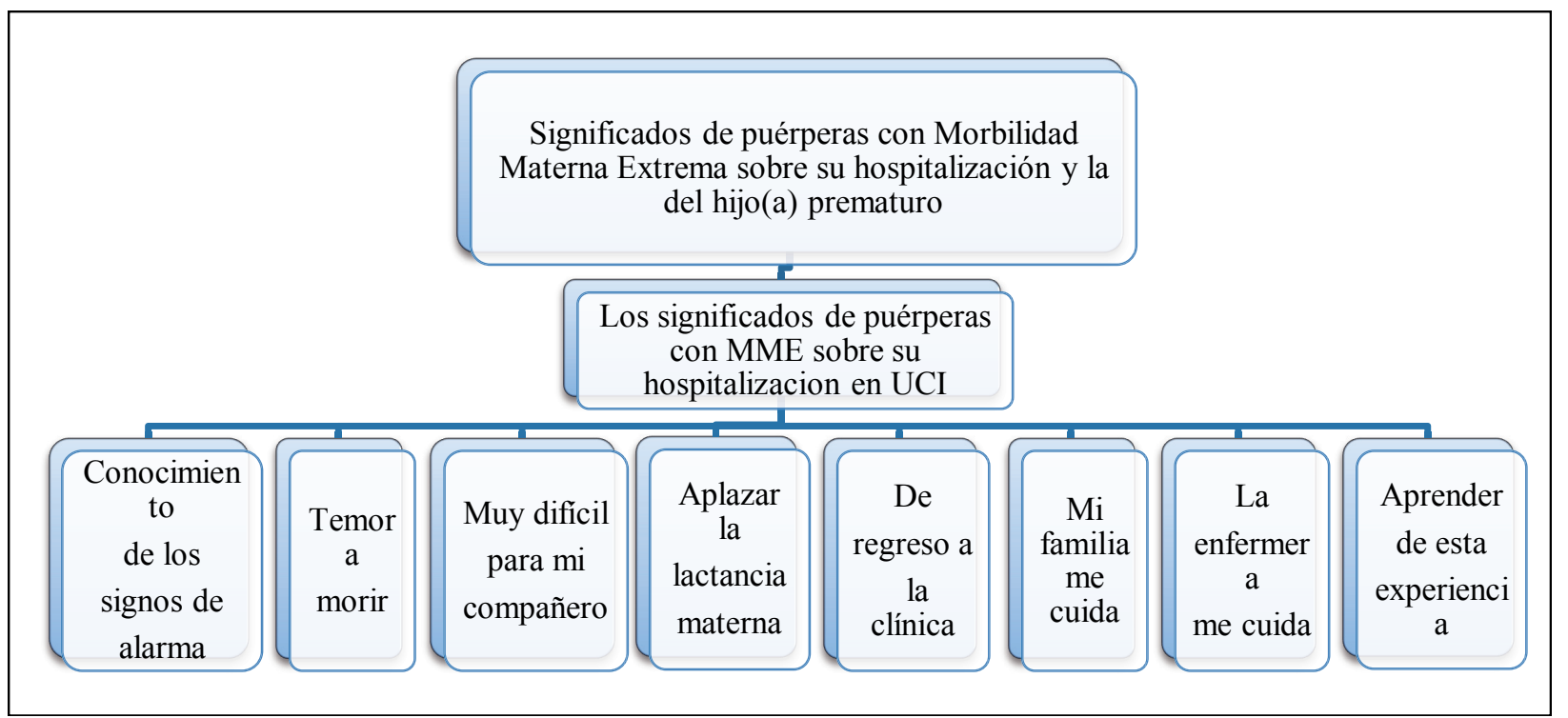

Figura 1. Os significados de puérperas com morbidade materna extrema internadas na UTI

Fonte: Processo da análise dos dados "Significados de puérperas com morbidade materna extrema sobre a sua internação e a do seu filho prematuro". Criada por Laura Osorio Contreras.

As puérperas compartilharam os seus saberes, crenças, costumes, comportamentos e tradições sobre o significado da internação na UTI. Estas informações concentraram-se em 8 domínios assim:

\section{Domínio 1: Conhecimento dos sinais de alarme}

Os resultados deste domínio mostraram que todas as puérperas conhecem e identificam os sinais de alarme durante a gravidez, atribuindo um significado particular com uma linguagem emic, como evidencia o depoimento:

"Dor de cabeça intenso, na frente e atrás além do monte de assovios, como se tivesse muitos bichos nos ouvidos e um pouco de luzes brilhantes que eu via"I4E1.
Desse modo a informação fornecida pelas informantes converteu-se no insumo para prestar cuidados de enfermagem mais eficientes e ensino em termos mais claros para as puérperas.

É preciso destacar que todas as informantes nomearam claros sinais e sintomas de alarme durante a gravidez, entretanto, algumas não prestaram maior atenção porque o profissional do atendimento falava que era "normal" ou escutavam isso de familiares e amigos.

Por outro lado, uma das informantes lembrou das práticas que a sua família prestou para outra parente grávida com inchaço nos pés:

"a minha mãe pegava água morna com sal de Epsom e me colocava os pés na bacia, e falava que ia abaixar o inchaço... Ela também pegava os meus 
ISSN-PRINT

1794-9831

E-ISSN 2322-7028

Vol. 16 No. 3

Sep - Dic 2019

Cúcuta, Colombia pés, fazia massagem com um creme para as dores à noite, depois que ela fazia a massagem eu acordava com os meus pés com um pouquinho menos de inchaço "I4E1.

Neste contexto a mãe foi a cuidadora que usou diferentes elementos (água morna, sal de Epsom e creme) para aliviar-lhe o edema. Estas práticas culturais desde o olhar da Leininger podem-se manter. A evidência científica mostra que o Sal de Epson (27) é o mesmo sulfato de magnésio e tem o efeito relaxante.

\section{Domínio 2: Medo de morrer}

Destacam-se aqueles significados que atribuem as informantes quando sabem que as suas condições de saúde são delicadas e que como consequência dessas condições, a sua gravidez vai ser interrupta prematuramente e além disso, que serão internadas na UTI. Este fato para elas implica o risco de morrer e portanto, aparece o medo, as lagrimas como é evidente no seguinte depoimento:

"O médico.... falou-me -tu vais direto para a UTI- $e$ quando ele diz aquilo eu fiquei com medo e escorreram as lágrimas, comecei chorar. Nesse momento eu pensei -Meu Deus!- já que eu vou morrer?, que irá acontecer comigo? porque o povo fala que quando a gente entra na UTI, te um pé no túmulo e outro de fora, eu fiquei com medo e comecei chorar',I1E2.

Um aspecto significativo neste domínio esteve relacionado com as manifestações de desesperação, solidão, não ter noticias dos filhos, desconforto por não conseguir dormir, os monitores e os diferentes procedimentos aos que são submetidas:

"Me enfiaram na UTI e foi como eu falei... uma experiência não muito grata porque eu lá trancada, monitorando à minha pressão, com os medicamentos, que não podia descer da cama porque estava com o sulfato de magnésio e tinha uma sonda e não podia me levantar da cama...bom, na segunda-feira o desespero total, eu não sabia se a minha filha tinha nascido bem, como tinha nascido?'J7E1.

O sentimento de medo à morte, provocou outros sentimentos como a culpa, pelo fato da sua gravidez estar em condições normais e ter concluído por uma complicação como a pré-eclâmpsia.

Além disso, as informantes informaram nas entrevistas que a sua internação na UTI foi uma experiência trau- matizante e difícil de esquecer, onde ainda estando de volta nos seus lares tem lembranças do sucedido.

Partindo dos anteriores depoimentos, o medo da morte está presente nelas desde o primeiro momento que são informadas da internação na UTI, gerando tristeza, choro, desesperação delírios e culpa, sempre dependendo do contexto particular de cada uma dessas puérperas.

\section{Domínio 3: Muito difícil para o meu parceiro}

Todas as puérperas contavam com o apoio do seu parceiro durante à gravidez e durante a internação, assim como nos cuidados do filho recém nascido prematuro. Do mesmo modo, destaca-se que alguns desses companheiros tiveram que deixar os seus serviços para acompanhar, receber informações médicas e dar apoio emocional às suas mulheres; este fato causou impacto nas finanças familiares, principalmente pelas dificuldades para custear os gastos gerados por terem as suas esposas e filhos recém nascidos ambos na UTI.

Entretanto, as informantes manifestaram que os seus parceiros demostraram ser incondicionais para elas e os seus filhos, vencendo as adversidades pela doença e dificuldades econômicas.

Igualmente, os companheiros das puérperas internadas passaram a se fazer cargo totalmente do trabalho do lar, fazer visitas à clínica, o cuidado do bebê prematuro e dos outros filhos.

"Foi muito forte o trabalho que teve que assumir o meu marido, porque a nossa filha era prematura e tinha que trocar as fraldas, dar mamadeira cada três horas, então apenas conseguia faze-la dormir, ele ia me acompanhar na clínica, estava correndo de um lado para outro...então ele teve, nós tivemos uma tarefa muito difícil nessa vez, bom, mais para ele porque eu estava lá 'I1E5.

\section{Domínio 4: Adiamento da amamentação}

Para as puérperas a internação dos seus filhos prematuros durante vários dias na UTI e na UTI neonatal significou adiar a amamentação, onde não tiveram a oportunidade de ter contato com os seus filhos imediatamente após o seu nascimento pelas condições de saúde de ambos: isto gerou a quebra da tradição da amamentação e o afastamento do filho, produzindo tristeza, e impotência, além do sentimento de não ter 
tido os seus filhos, pela perda do toque com os seus bebês, amamentar-lhes logo que nasceram.

"Uffa me sinto um pouco triste, porque você sabe, logo que nasce o seu bebê, você quer pegar ele no colo, dar de mamar, tudo, e quando eu não podia.... me faz sentir um pouco impotente, mas... "I2E1.

Algumas das crenças das puérperas eram que o leite materno não sairia e que não o produziriam mais, porque os seus bebês não estavam sendo amamentados, por isso extraíram o seu leite de forma manual ou usando extratores, tomavam bebidas para melhorar a quantidade do leite como leite com rapadura, aveia, gergelim, sopas e líquidos, que eram práticas culturais herança dos seus familiares e conhecidos.

"Os primeiros dia ficaram duros, agora que estava aqui estavam ficando cheios e tirava o meu leite e saia, já não quer descer, então a minha mãe está fazendo um leite com rapadura para eu tomar, porque isso ajuda o meu leite descer" I1E2.

Outro grupo de puérperas se privaram de amamentar os seus filhos prematuros pelo medo de que os medicamentos causaram dano aos seus bebês, para o que extraiam o leite e jogavam fora, ação que as fazia sentir mal.

\section{Domínio 5: Voltar à clínica}

Duas das informantes presentaram complicações na ferida cirúrgica, obrigando-as a procurar atendimento na unidade de emergência; outra foi ré-internada na UTI pela pressão arterial, significando para elas a sensação de inutilidade ao deixar os seus parceiros com a carga do lar.

Voltar à clinica gerou sensações negativas, ao serem internadas por segunda vez voltam a apresentar a solidão, sentimento de abandono das suas famílias, curativos doloridos, punções, e possíveis procedimentos cirúrgicos.

"Pois menina, imagine-se, quem vai pensar que a ferida vai se infectar e que tem que voltar a ser internado, deixar as crianças sozinhas e o marido com toda essa carga, onde ele precisa trabalhar para o sustento e cuidar das crianças, isso é puxado!, estar atento da sua mulher que está na clínica, levar-lhe água, a comida ou alguma coisa, então a gente se sente inútil’I5E2.
Outra participante voltou à clinica para atendimento com o cardiologista, esse acompanhamento fez ela se sentir importante e contente, principalmente porque as enfermeiras que acompanharam a sua internação lembraram dela, evidenciando o cuidado compassivo que a equipe de enfermagem prestou a ela.

"Agora que cheguei, todas as enfermeiras chegaram em mim, me cumprimentaram, todas me conheciam, pensei que não iam se lembrar de mim!, me cumprimentaram, me abraçaram, me beijaram...ou seja, nessa hora me senti importante!!! (risos) me senti contente"'I2E2.

\section{Domínio 6: A minha família cuida de mim}

As visitas domiciliares e as entrevistas evidenciaram que todas as informantes do estudo tiveram apoio familiar durante a internação delas e dos seus filhos recém nascidos; igualmente, tiveram ajuda para as tarefas do lar, o cuidado dos filhos e burocracia do atendimento em saúde (autorizações, dispensário de medicamentos), permitindo-lhes guardar repouso físico durante os primeiros 45 dias do pós-parto (período que apelidam como "dieta"), contribuindo com a sua recuperação.

Do mesmo modo, observou-se que os conhecimentos culturais que fornecem os familiares e pessoas próximas às informantes são valiosos para a sua recuperação, já que a sua finalidade é prestar o bem-estar físico.

"Por exemplo, aqui me fazem as sopas...que não tome refrigerante nem coisas assim, porque tudo isso passa para o meu filho, então procuro comer coisas que me nutram a mim e o bebê para quando o amamente, a sopa.... bastante peixe."I3E1.

Outra das recomendações que recebiam as puérperas dos seus parentes e que tem uma alta carga cultural , é evitar a friagem e cumprir com a "dieta".

"O cuidado da casa, de não fazer limpeza, levantando-me, tinha a minha sogra que me dizia -a mulher que pariu precisa jantar logo cedo- então jantar cedo, tomar banho, também ela diz que não podia tomar banho à tarde, crença de velho, mas (risos) somente o banho de manhã, na tarde Deus me livre! a friagem, tinha a minha sogra falando que não podia pegar friagem, não podia tomar banho à noite’'I9E2. 
ISSN-PRINT

1794-9831

E-ISSN 2322-7028

Vol. 16 No. 3

Sep - Dic 2019

Cúcuta, Colombia

\section{Domínio 7: A enfermeira cuida de mim}

É o domínio mais significativo do estudo, destaca o suporte social relacionado com o apoio institucional percebido pelas puérperas por parte das profissionais e técnicas de enfermagem durante a internação na UTI. Elas destacam a administração de medicamentos, o banho, o curativo da ferida cirúrgica, cuidado nos seios e a extração do leite materno, o monitoramento dos sinais vitais e o apoio emocional prestado às puérperas nos momentos de tristeza, angustia e solidão.

"As enfermeiras eram carinhosas, elas eram muito de boa, cada momento perguntavam como me sentia, levavam os medicamentos, iam me ver pressão, colocavam coisas nos meus seios para que não saisse o leite, punham tipo uma proteção...quando sentia frio pegavam lenções para mim, eu me senti muito bem atendida"'I4E1.

Foram vários os depoimentos que exaltaram o cuidado compassivo das enfermeiras e o cuidado centrado na pessoa e a sua família.

"As enfermeiras faziam-me o favor de me dar banho, me tratavam com cuidado de não machucar a ferida, quando precisavam fazer a troca dos lençóis, igual, era numa delicadeza, pedindo licença um momento, não chegavam bravos pelo fato de eu estar ai, ou quando um parente, dois e até três vinham me visitar" I3E1.

$\mathrm{O}$ ensino prestado à puérpera com MME no momento da saída, precisou de informações detalhadas para garantir a pronta e ótima recuperação da sua saúde. Para elas foi importante receber a informação verbal que receberam sobre os cuidados da ferida, toma da pressão arterial, atividade física, alimentação, toma de medicamentos, trâmites para consultas e procedimentos a serem feitos no sistema de saúde, assim como a empatia que sentiram pelas enfermeiras permitiu esclarecer dúvidas e foi mais simples para as pacientes e familiares realizar as respectivas gestões.

"Disseram-me que tinha que ficar de repouso... além do cuidado da ferida da cesariana, o lavado... fazer umas aferições da pressão cada 12 horas, tinha que fazer as anotações num papel, com a hora, a data e a pressão como estava, depois disso tinha que agendar uma consulta com o ginecologista e levar o papel para ele conferir'"I3E2.

\section{Domínio 8: Aprender dessa experiência}

Para as puérperas com MME ter ficado internadas na UTI depois do nascimentos dos seus filhos significou "não descuidar a sua saúde".

"Opa! isto me deixou um ensinamento bem grande, que a gente não pode nunca se descuidar com a saúde....porque se eu estivesse mais esperta do que estava acontecendo comigo...provavelmente não teria passado por tudo isso...tenho que ficar de esperta"'I2E1.

Segundo o expressado pelas puérperas durante as suas entrevistas, a experiência na UTI e no nascimento do novo filho as fez valorizar mais as suas famílias. Igualmente foi uma descoberta importante dentro dos significados da internação para as puérperas com MME, valorizando o trabalho da equipe de enfermagem.

"Aqui aprendi....ver as enfermeiras de um jeito diferente... as que estiveram comigo na internação, excelentes essas meninas, a atenção de todas, eu pude perceber que, não são todas, as que me receberam na primeira noite até trançaram os meus cabelos...porque quando uma enfermeira faz trança nos cabelos ...isso mudou o conceito que eu tinha dessa profissão... achei um trabalho bonito, excelente"I9E2.

O presente estudo evidenciou que as puérperas tiveram certeza que Deus não tinha as abandonado em momento nenhum da internação.

"O tempo tudo eu estive prendida de Deus, porque pensava - Senhor, se tu me deste essa criatura depois de tantas adversidades, eu não tinha como ficar grávida, tanta complicação que tive na gravidez...então lhe dizia si Ele tinha me presenteado, tinha me dado, não podia tirar assim, porque Ele tinha me presenteado" I6E1.

Os achados desse domínio são contribuições significativas das mães à sociedade, às politicas de saúde, a academia e a pesquisa científica. São experiências do sentido da vida perante a internação numa UTI e dispor de uma nova oportunidade para preservar e cuidar da sua saúde.

O significado atribuído pelas informantes na sua própria linguajar (emic) podem-se traduzir nos termos da área da saúde: "desligar-se"(o Pomeroy), 
"abotigados"(com edema), "esfregar-se os pés" (fazer massagem), "balde d'água fria" (noticia inesperada), "barulho de aparelhos"(alarme dos monitores), entre outros. Esta relação de entre os significados das expressões representam a proximidade dos profissionais aos saberes populares próprios da cultura das puérperas para prestar-lhes o cuidado congruente.

$\mathrm{Na}$ teoria de Leininger, podem estabelecer-se três tipos de cuidados culturais: conservação, adaptação e reestruturação, Nos depoimentos das puérperas puderam ser apreciados conhecimentos e práticas culturais apreendidas da família, amigos e vizinhos. As seguintes expressões podem conservar-se já que não prejudicam a saúde das puérperas: enfiar os pés com inchaço na água quente com sal de Epsom, esfregar-se os pés com creme, comidas baixas no sal e na gordura, tomar suco de agraz (fruta da região) para aumentar a hemoglobina, tomar leite com rapadura, aveia gergelim, sopas e sucos para melhorar a descida do leite materno, proteger-se da friagem durante o puerpério. Por outro lado a prática de não amamentar ao recém nascido e jogar fora o leite quando estiver tomando medicamento para a pressão deve-se corrigir, a evidência científica demonstra que estes medicamentos são seguras para as mães e as crianças que amamentam (28). A aceitação dessas práticas pela enfermeira e demais membros da equipe de saúde contribuem a prestar à puérpera o cuidado congruente acompanhado da família permitindo uma ótima recuperação do seu estado de saúde.

\section{Discussão}

Os significados derivados da internação da puérpera na UTI são de grande valor para todos os profissionais de saúde que trabalham com mulheres gestantes.

Estes resultados comprovam que desde a gravidez, a mulher identifica sinais de alarme, neste ponto Pérez e col (29) afirmam que para a grávida ter claridade sobre os sinais de alarme fazem que elas atuem de maneira rápida e eficaz, permitindo minimizar consequências mais severas, o que é possível através do compromisso e o trabalho em equipe de todos os profissionais que direta o indiretamente tem contato com a gestante.

Por outro lado, os profissionais da saúde que realizavam o acompanhamento no pré-natal, subestimavam os sinais e sintomas de alarme relatados pelas pacientes, gerando práticas inadequadas nas gestantes como acreditar que a cefaleia, a epigastralgia, o barulho nos ouvidos, os fosfenos, entre outros eram normais e portanto procuravam atendimento tardiamente nas unidades de emergência. Neste ponto é importante afirmar que os transtornos hipertensivos da gravidez se presentam no $60.5 \%$ do total de pacientes e é a primeira causa de mortalidade materna (30), fortalecendo a importância de estudos na MME.

As guias de cuidado de enfermagem no acompanhamento pré-natal da secretaria de saúde distrital de Bogotá, Colômbia (31), recomendam aos enfermeiros que realizem este acompanhamentos fornecendo educação específica à gestante sobre sinais de alarma como dor de cabeça, febre, escutar assovios nos ouvidos, visão embaçada ou com luzes, inchaço no rosto, tosse, obstrução nasal, choro, tristeza ou depressão, redução dos movimentos do bebê, inchaço nos pés, entre outros.

Os sentimentos que surgiram após a internação na UTI, Laza e col (32), sugere que para as gestantes as condições patológicas causantes de uma gravidez de alto risco são percebidas como preocupantes, de gravidade, ameaçantes para a sua vida e a dos seus filhos, igualmente, estar internadas durante vários dias é perturbador e faz surgir sentimentos de raiva, frustração e solidão.

Os depoimentos obtidos destacaram que o medo tem um significado importante durante a experiência de internação da puérpera na UTI, encontrando-se intimamente ligado à desinformação, muitas vezes estar na UTI com monitoramento permanente é associado com um estado de saúde extremamente grave que gera sensações de tristeza e desesperação. $\mathrm{O}$ anterior se relaciona com os achados de Vasconcelos de Azevedo e col (12), que afirmaram que as pacientes gostariam de receber maiores informações sobre as condições da sua saúde, reduzindo os seus medos e ter um maior autocuidado.

A sensação de desespero, a solidão e o desconforto na UTI foram variáveis que Laza \& Pulido (33) identificaram nas mães, o sentimento de não estarem com os seus filhos produz solidão, ansiedade e depressão, igualmente influíram as diferentes procedimentos aos que eram submetidas como: a administração de medicamentos, as múltiplas punções e o acesso vesical, ações que causavam dor e desconforto.

Fatos como: não conhecerem os seus filhos recém nascidos prematuros e estarem internados na UTI 
ISSN-PRINT

1794-9831

E-ISSN 2322-7028

Vol. 16 No. 3

Sep - Dic 2019

Cúcuta, Colombia neonatal, o adiamento da amamentação e ruptura desse vínculo especial, produz a sensação de não serem mães; para o que Ocampo (34) afirmou que o desapego do neonato gera vazios e a sensação de ter tido um filho que não é delas. Neste ponto Byrne e col (35) sugeriram que as mães que mantem a amamentação embora esta traumática situação, conseguem ter a sensação de controle e reforçam o vínculo mãe-filho.

O traumatizante da experiência de internação na UTI foi descrito previamente por Elmir e col (10), eles afirmaram que um grupo de puérperas histerectomizadas de emergência por hemorragia pós-parto, experimentaram lembranças após o procedimento e isso repercutiu no estado de ânimo, a incorporação à vida familiar e social dessas mulheres.

Pelo descrito anteriormente, reforça-se a importância do apoio do parceiro e a família, principalmente neste estudo as puérperas qualificaram como imprescindível receberem visitas na internação, apoio nas tarefas do lar, do cuidado dos outros filhos, na alimentação e cuidado da puérpera ao voltar à casa além do sustento económico.

Soares e col. (36) destacaram como dever dos pais prover bem-estar à sua família, incluindo o suporte emocional à esposa durante a permanência hospitalar assim como fornecer recursos financeiros para o sustento do lar. Igualmente Prieto \& Ruiz (37) afirmaram que as mulheres puérperas devem guardar repouso durante os primeiros quinze dias da "dieta" evitando desenvolver tarefas domésticas como varrer, passar pano, lavar ou passar roupas, além disso não devem se expor à friagem que pode gerar problemas de saúde para elas e o recém nascido.

Em relação aos conhecimentos e conselhos das mães, avós e tias respeito à amamentação, foram consideradas de utilidade especialmente para incrementar a produção do leite. Afirmando estes conhecimentos, previamente Prieto (37), Castiblanco (18) e García (38), informaram que as puérperas consomem infusões de plantas como o Foeniculum vulgare, canela, mamão papaia, gengibre, linhaça, rapadura e leite; que as mães apontam serem de ajuda para melhorar a produção de leite materno enquanto elas estavam internadas na UTI e os seus filhos na UTIN.

Neste ponto, o modelo do sol nascente proposto por Leininger permitiu classificar os resultados obtidos segundo os seguintes fatores: equipamentos, sondas e procedimentos (tecnológicos), apegar-se de Deus (religiosos), apoio do parceiro, irmãs, sogra ou cunhada (familiares), os "encaminhados para UTI estão prestes a morrer" (culturais e crenças), "demora tempo demais o atendimento pelo médico especialista" (político-legal), aumentaram os gastos (económico) e "a enfermeira me explicou" (educativos).

Cabe destacar que um dos significados mais especiais para as puérperas durante a internação na UTI foi aprender a dar valor: ao trabalho das enfermeiras, à vida, à saúde e do vínculo com Deus.

Neste ponto, o trabalho da equipe de enfermagem foi fundamental ao prestar atenção pelas 24 horas do dia, fornecendo cuidados, suporte emocional e companhia. Nas perguntas associadas com o conforto, as puérperas consideravam que eram manifestações de cuidado e empatia por parte das enfermeiras (os). Sobre estes sentimentos Álvarez (39), evidenciou que puérperas com hemorragia no pós-parto destacam o cuidado, a delicadeza na realização de procedimentos, estarem atentas das refeições, e administrar os medicamentos nos horários certos dentro das atividades importantes da equipe de enfermagem. Do mesmo modo, Hinton e col. (40) destacaram que as puérperas internadas na UTI após terem complicações derivadas da gestação qualificaram como importantes a bondade e apoio recebido pela equipe de enfermagem, permitindo que a experiência fosse mais fácil de levar qualificando-as como "anjos impecáveis".

Ainda no sentimento de dar valor, Elmir (41) no seu estudo evidenciou que as mulheres histerectomizadas por uma hemorragia pós-parto a experiência de sobrevivência as fez dar maior valor à vida, às suas famílias e fazerem as coisas que sempre tinham querido, além disso, valorizar o privilegio da maternidade, sendo considerada a experiência como uma nova oportunidade para o cuidado da saúde e adoção de novos estilos de vida, chamando-a como uma "segunda oportunidade".

Em relação com a proximidade com Deus, Cavalheira e Col. (42) afirmaram que para as puérperas com MME a fé é muito importante, a crença em Deus fornece a força necessária para vencer as adversidades de saúde. As informantes do presente estudo sentiram a presença do amor de Deus na recuperação da sua saúde e a dos seus filhos prematuros. 


\section{Conclusões}

- Os significados que tem a internação na UTI para mulheres puérperas com MME são influenciados por múltiplos saberes, crenças e tradições que evidenciam a maneira como elas sobreviveram e os ensinamentos que a experiência lhes gerou.

- Evidenciou-se que as puérperas conhecem os sinais e sintomas de alarme, entretanto, os profissionais que acompanham o seu pré-natal subestimam esses sinais.

- O medo de morrer é um sentimento universal em todas as puérperas que são internadas na UTI, elas associam esse encaminhamento com condições de saúde graves, estando ao borde da morte. Entretanto, ao sobreviverem à experiência é a oportunidade para não descuidar a sua saúde no futuro.

- Embora a amamentação tivesse sido adiada, as puérperas praticavam rituais orientados pelas suas famílias para garantir a produção do leite materno, tais como: beber leite com rapadura, aveia, gergelim, sopas, liquido entre outros alimentos.

- Os conhecimentos culturais relacionados com o consumo de sopa de peixe, jantar cedo, evitar a friagem, cumprir com as precauções da "dieta", entre outras, são tradições valiosas que são herança das suas famílias e pessoas próximas, legado que deve ser considerado pelos profissionais de saúde, para prestar melhores cuidados às pacientes.

- A presente pesquisa confirmou o cuidado compassivo, humano, afetuoso e competente da equipe de enfermagem com as pacientes com MME quando estavam internadas na UTI, assim como o respeito pelas suas crenças culturais.

\section{Conflito de interesses}

As pesquisadoras declaram não ter conflito de interesses.

\section{Referencias Bibliográficas}

1. Organización Mundial de la Salud. Mortalidad materna. Nota descriptiva $N^{\circ} 348$ noviembre de 2015 [Internet]. OMS; 2015 [consultad o 3 de mayo de 2019]. Disponible en: https://www.who.int/es/newsroom/fact-sheets/detail/maternal-mortality

2. Organización Panamericana de la Salud. Organización Mundial de la Salud. Mortalidad materna es inaceptable. Abril 2019. [consultado 3 de mayo de 2019]. Disponible en: https://www.paho.org/col/ index.php?option=com content\&view $=$ article $\&$ id $=3165$ :la-mortalidad-materna-es-inaceptable-ginatambini\&Itemid $=551$

3. Instituto Nacional de Salud. Boletín epidemiológico 2019. [consultado 3 de mayo de 2019]. Disponible en: https://www.ins.gov.co/buscador-eventos/BoletinEpidemiologico/2019\%20Bolet $\% \mathrm{C} 3 \% \mathrm{ADn} \% 20$ epidemiol\%C3\%B3gico\%20semana \%201.pdf

4. República De Colombia. Ministerio de Salud y Protección Social. Instituto Nacional de Salud. Protocolo de vigilancia en Salud Pública. Morbilidad Materna Extrema [Internet]. Bogotá D.C: INS; 2016 [consultado 3 de mayo de 2019]. Disponible en: https://www.dadiscartagena.gov.co/images/docs/saludpublica/vigilancia/protocolos/p2018/pro_morbilidad_materna_extrema_2018.pdf

5. Instituto Nacional de Salud - Proceso Vigilancia y Análisis del Riesgo en Salud Pública. Informe del Evento Morbilidad Materna Extrema, hasta el periodo epidemiológico 13, Colombia 2017 [Internet]. Bogotá D.C: INS; 2017 [consultado 03 de mayo de 2019]. Disponible en: http://www.ins.gov.co/ buscadoreventos/informesdeevento/morbilidad\%20materna\%20extrema\%20pe\%20xiii\%202017.pdf

6. Ortiz E, Ludmir J. Where do we go in terms of safety and quality of obstetric care in Colombia? Colombia Médica 2016; 47(1): 9-10.

7. Instituto Nacional De Salud. Boletín epidemiológico semanal. Semana 52 de 2017 [Internet]. Bogotá D.C: INS; 2017 [consultado 19 de febrero de 2018]. Disponible en: https://www.ins.gov.co/buscadoreventos/BoletinEpidemiologico/2017\%20Bolet $\% \mathrm{C} 3 \% \mathrm{ADn} \% 20$ epidemiol\%C3\%B3gico\%20sema$\underline{\text { na\%2052.pdf }}$ 
ISSN-PRINT

1794-9831

E-ISSN 2322-7028

Vol. 16 No. 3

Sep - Dic 2019

Cúcuta, Colombia
8. Jurado N. Factores de riesgo para morbilidad materna extrema en gestantes. [Trabajo de Grado Especialización]. Bogotá D.C: Universidad del Rosario; 2014.

9. Dunning T, Harris JM, Sandall J. Women and their birth partners' experiences following a primary postpartum haemorrhage: a qualitative study. BMC Pregnancy and Childbirth 2016; 16 (80):1-10.

10. Elmir R, Schmied V, Jackson D, Wilkes L. Between life and death: women's experiences of coming close to death, and surviving a severe postpartum haemorrhage and emergency hysterectomy. Midwifery 2012; 28 (2):228-35.

11. Furuta M, Sandall J, Bick D. Women's perceptions and experiences of severe maternal morbidity - A synthesis of qualitative studies using a meta-ethnographic approach. Midwifery 2014; 30 (2): 158-69.

12. Vasconcelos De Azevedo D, De Araújo A, Costa I. An analysis of the meanings of pre-eclampsia for pregnant and postpartum women and health professionals in Rio Grande do Norte, Brazil. Midwifery 2011; 27 (6): 182-87.

13. Ospina A, Muñoz L, Ruiz de Cárdenas C. Coping and adaptation process during puerperium. Colombia Médica. 2012; 43 (2); 167-74.

14. Cárdenas R. Acciones y programas para la reducción de la mortalidad materna: ¿qué necesitamos hacer? Salud Publica Mex. 2007;49(2):231-3

15. González Ortiz LD, Gómez Arias RD, Vélez Álvarez GA, Agudelo Londoño SM, Gómez Dávila J, Wylie J. Características de la atención hospitalaria y su relación con la morbilidad materna extrema en Medellín, Colombia. Rev Panam Salud Publica. 2014;35(1):15-22.

16. Carrillo Franco J, García Balaguera C. Comportamiento de la morbilidad materna extrema en el departamento del Meta, Colombia, 2014. Hacia promoc. salud. 2016; 21(1): 15-25.

17. Marín Blandón A, Dussán Lubert C, González J, Benjumea M, Arengas I. Mortalidad materna en el departamento de Caldas (Colombia), durante el quinquenio 2004-2008. Hacia la Promoción de la Salud. 2010; 15(1) :110-126.

18. Castiblanco Lopez N, Muñoz de Rodríguez L. Visión de las madres en el cuidado del hijo prematuro en el hogar. Av en Enferm [Internet]. 2011 [Consultado 20 Marzo 2018]; 29(1):120-9. Disponible en: http://revistas.unal.edu.co/index.php/avenferm/article/view/35865

19. Hoyos Vertel LM. Creencias y prácticas de cuidado cultural de mujeres con morbilidad materna extrema. [Tesis de Maestría]. Bogotá: Universidad Nacional de Colombia; 2017.

20. Leininger, M. McFarland, M. Culture care diversity and universality: A worldwide nursing theory. Jones y Bartlett Learning. 2006.

21. Osorio LV. Significados de puérperas con Morbilidad Materna Extrema sobre su hospitalización y la del hijo(a) prematuro [Tesis de Maestría]. Bogotá: Universidad Nacional de Colombia; 2018.

22. Sagar PL. Madeleine Leininger's Theory of Culture Care Diversity and Universality. En: Sagar PL. Transcultural Nursing Theory and Models: Application in Nursing Education, Practice, and Administration. New York: Springer Publishing Company; 2012. 1-17.

23. Leininger MM. Culture care diversity and universality: a theory of nursing. New York: Nacional league for nursing Pres; 1991.

24. McFarland MR, Mixer SJ, Webhe H, Burk R. Ethnonursing: A Qualitative Research Method for Studying Culturally Competent Care Across Disciplines. International Journal of Qualitative Methods 2012; 11 (3): 259-79.

25. Hernández R, Fernández C, Baptista MP. Metodología de la investigación 5 ed. México D.F.: Mc Graw-Hill; 2010.

26. Spradley J. The ethnographic interview. Orlando: Harcourt Brace Jovanovich College Publishers; 1979.

27. Sakula A. Doctor Nehemiah Grew (1641-1712) and the Epsom salts. Clio Medica (Amsterdam, Netherlands). 1984, 19(1-2):1-21 
28. Ortiz R, Rendón C, Gallego C, Chagüendo J. Hipertensión/preeclampsia postparto, Recomendaciones de manejo según escenarios clínicos, seguridad en la lactancia materna, una revisión de la literatura. Rev. Chil. Obstet. Ginecol 2017; 82(2):219-31.

29. Pérez J, Cuevas E, García S, Campo A. Maternal near miss morbidity in Colombia: variables related to opportune access to health care related to the number of inclusion criteria. Revista Facultad de Medicina 2014; 62 (4): 553-58.

30. Noticias. Preocupantes cifras de mortalidad materna en Colombia. Sept. 2015. [consultado 3 de mayo de 2019]. Disponible en: https://noticias.canalrcn.com/nacional-pais/preocupantes-indices-mortalidad-materna-colombia

31. Castiblanco N, Acosta S, Bejarano N, Bejarano M, Castañeda L, et al. Guía de cuidado de enfermería en control prenatal. Enfermería Basada en la Evidencia (EBE) [Internet]. Bogotá D.C.: Secretaria Distrital de Salud; 2015 [consultado 03 de mayo de 2019]. Disponible en: http://www.saludcapital.gov.co/ DDS/Guas\%20de\%20cuidado\%20de\%20enfermera/Guia\%20prenatal.pdf

32. Laza Vásquez C, Pulido Acuña G, Castiblanco Montañez RA. Peligro, muerte y secuelas: percepción de la preeclampsia severa por quienes la han vivido. Enfermería Global [Internet]. 2014 [consultado 29 de abril de 2017]; 13(2): 481492. Disponible en: http://www.redalyc.org/articulo.oa?id=365834853022

33. Laza Vásquez C, Pulido Acuña G. La vivencia de la pre-eclampsia: una dura travesía para la cual no se está preparada. Rev. Univ. Ind. Santander. Salud [Internet]. 2014 [consultado 29 de abril de 2017]; 46(2): 159-168. Disponible en: http://www.scielo.org.co/scielo.php?script=sci_arttext\&pid=S0121$\underline{08072014000200007 \& \operatorname{lng}=\text { en }}$

34. Ocampo MP. El hijo ajeno: vivencia de madres de niños prematuros hospitalizados. Aquichán 2013; 13(1): 69-80.

35. Byrne V, Egan J, Pádraig MN, Sarma K. What about me? The loss of self through the experience of traumatic childbirth. Midwifery 2017; 51: 1-11.

36. Soares RL, Christoffel MM, Rodrigues E, Machado ME, Cunha AL. Being a father of a premature newborn at neonatal intensive care unit: from parenthood to fatherhood. Esc. Anna Nery 2015; 19(3): 409-16.

37. Prieto B, Ruiz C. Significados durante el puerperio: a partir de prácticas y creencias culturales. Aquichán 2013; 13(1): 7-16.

38. García DS, Castiblanco N. Significado de la lactancia materna en puérperas con niño(a) en programa canguro ambulatorio. [Tesis de Maestría]. Bogotá D.C.: Universidad Nacional de Colombia; 2017.

39. Álvarez Franco CC. Cómo describen el cuidado de enfermería las mujeres que presentaron hemorragia postparto. Aquichan 2013; 13(1): 17-26.

40. Hinton L, Locock L, Knight L. Maternal critical care: what can we learn from patient experience? A qualitative study. BMJ Open 2015; 5 (4):1-9.

41. Elmir R. Finding meaning in life following emergency postpartum hysterectomy: what doesn't kill us makes us stronger. J Midwifery Women's Health 2014; 59 (5): 510-15.

42. Carvalheira A, Tonete V, Parada C. Sentimientos y percepciones de mujeres en el ciclo embarazo-puerperio que sobrevivieron a una morbosidad materna grave. Rev. Latino-Am. Enfermagem [Internet]. 2010 [consultado 28 de mayo de 2018]; 18(6). Disponible en: http://www.scielo.br/ scielo.php?script $=$ sci arttext\&pid $=$ S010411692010000600020\&lng $=$ en 